\title{
Talcott Parsons' AGIL Schema-based System Identification of Administrative Problems of North-East Vocational Education in Thailand*
}

\author{
Surachai Tumtavitikul \\ Thammasat University, Bangkok, Thailand
}

\begin{abstract}
Talcott Parsons was a great well-known sociologist whose approach was based on system theory. He identified social system into subsystems which were A (Adaptation functions), G (Goal gratification functions), I (Integration functions), and L (Latent pattern maintenance functions). His approach was based on the concern for the stability or maintenance of social system. The aim of this research is experimentally to identify the social system of north-east vocational education's macro administrative problems in Thailand by utilizing AGIL schema. The writer has adopted the symbiosis or maintenance of socials system stance by utilizing this approach. The results of the research were, firstly, the major macro vocational education eight problems (sentences) and 27 sub-problems (sentences) and secondly, the 15 diagrams of above-mentioned problems and sub-problems after utilizing AGIL concepts (In this paper, the writer illustrated seven of them). The study had been done using both secondary and primary data. The secondary data were collected from the written documents and from the internet concerning the vocational schools. In depth interview data were collected. Some respondents have been interviewed more than once. The total of 69 times in depth interview were collected. The researcher had utilized Japanese Kawakita Jiro Method of processing scattering paper clips from these primary and secondary data. In conclusion, the detail of main findings, system of sentences of the macro problems, some derived diagrams examples (After AGIL schema applying) and also implication from the main findings have been illustrated.
\end{abstract}

Keywords: AGIL schema, Talcott Parsons, north-east vocational education, Thailand

\section{The Significance of Public Vocational Colleges and the Aim of This Study}

Up to recently the graduates from vocational colleges (two years or four years school system after graduating from junior high school (Grade 9)) have been the "doers" of almost every economic activities including service sectors. The main vocational education in Thailand is implemented by government. Thus, the question what enhance and hinder the development of public vocational colleges in Thailand is as significant as question into the strength and weakness of Thai economical activities themselves and also the question into the

\footnotetext{
* Project Supported: Institute of Human Research, Thammasat University, Thailand.

Surachai Tumtavitikul, Associate Professor, Department of Operation Management, Thammasat Business School, Thammasat University.

Correspondence concerning this article should be addressed to Surachai Tumtavitikul, Department of Operation Management, Thammasat Business School, Thammasat University, 2 Prachan Rd., Pranakorn, Bangkok, 10200, Thailand. E-mail: suratum@tu.ac.th.
} 
performance of public administration itself.

The aim of this research is experimentally to identify the social system of north-east vocational education's macro administrative problems in Thailand by utilizing AGIL schema. The writer has adopted the symbiosis or maintenance of social system stance by utilizing this approach.

\section{The Motives and Aspects of the Study}

The study had aimed at system identification of the administrative characteristics and problem of the north-east vocational colleges in Thailand. The study had done using both secondary and primary data. In depth interview data were collected from more than 20 directors, deputy directors of the north-east vocational colleges and 10 government employees from the Ministry of Education on the administrative problems. Some respondents have been interviewed more than once. The total of 69 time of depth interviews (short of long) were collected from these three groups. Notingly, the interviews themselves are one of the main objectives.

The motive of the study is an experimental study of hypothesis creation process by utilizing Talcott Parsons' AGIL schema in system identification in order to maintain the social system.

The experimental discussion related to how to identify social systems from the perspective of relationalism or specifically the diagram (two dimensions) presentation of the social systems from the perspective of symbiotical macro operations including some issues related to methodological problems.

\section{Approaches to Methods of the Study}

The study on system identification of the administrative problems of the north-east vocational colleges in Thailand had been done using both secondary and primary data. The secondary data were collected from the written documents and from the internet concerning the vocational colleges. The primary data were from the depth interview as mentioned before.

The study fully employed the Talcott Parsons' AGIL schema which was elaborated in diagram by Kazuo (1974). The reasons of this employment not other sociologists will be discussed in Appendix Figure A1.

The study fully employs the simple K.J. method invented by Kitagawa Jiro of Japan (prevalent in operation management) in gathering, analyzing, and idea creating of the data which will be presented in the same next section.

The overall analysis and writing of the diagrams will be implied after elaborated explaining of AGIL schema and K.J. method in next section.

\section{The Introduction of AGIL Schema and K.J. Method}

\section{AGIL Schema}

Talcott Parsons was a great well-known sociologist whose approach was based on system theory. He identified social system into subsystems which were A (Adaptation functions), G (Goal gratification functions), I (Integration functions), and L (Latent pattern maintenance functions). His approach was based on the concern for the stability of social systems.

More elaborately, Talcott Parsons concerned the maintainance of the social system by noted that it could be done by responding to function of each A-G-I-L subsocial systems.

Adaptation function is to realize the main needs of obtaining material (or money) of the system by material production or service production (in this case of vocational education). This is the main function of the 
social system in order for human to adapt to the environment. Conventional speaking, this is economic function.

Goal gratification function is to create the aims and mobilize resources in order to gratify this. Example in our case is the mobilizing personnels to create a vision or plan. Or the soft power utilization of creating unity among personnel's by mobilization Thai dancing event. This might be politic function.

Integration function is to implementing goal gratification by realizing it in forms of law, regulation or in the detailed agenda or other else in order to integrate the systems.

Latent pattern maintenance function is to maintain or create, or process the latent pattern inside the systems which is usually called "culture" or "education". For example, the act of religion ceremony or preaching.

The main hypothesis of this study is that no role-based actions which could be eluded from these systems.

The next hypothesis of this study's AGIL diagrams is that actions in these A-G-I-L system are not excluded between subsystems. That means they could be redundant.

These A-G-I-L functions are main functions which could be hierarchies into subsystems as Figure 1. By Kazuo (1974), Figure 2 is created.

Thus the real functionings are done in dotted sub-diagrams. Experimently, the main systems of each A-G-I-L might be "agents".

Further more discussion of AGIL schema comparing to other approach will be in Appendix Figure A1.

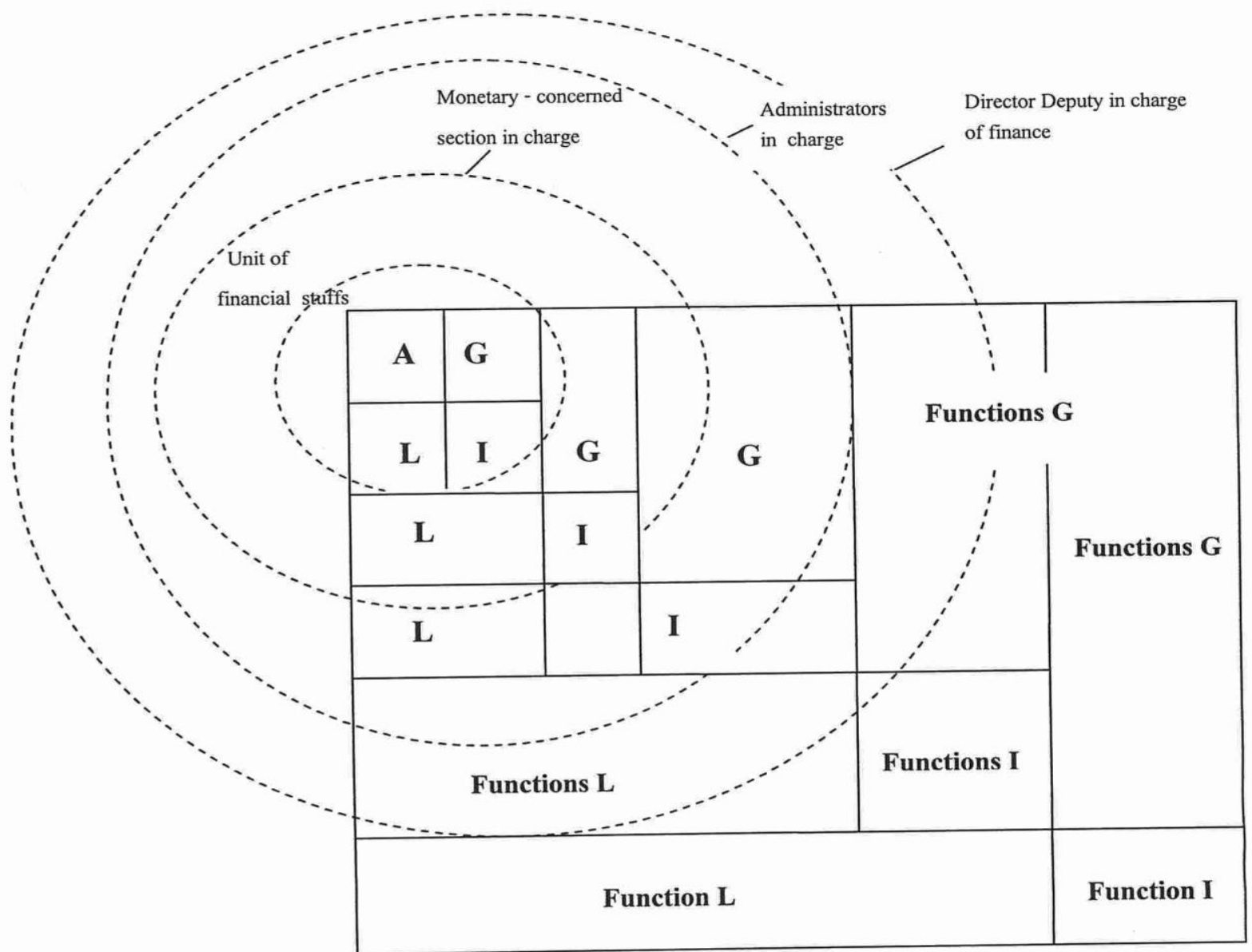

Figure 1. Hierarchies of the AGIL subsystems' example in vocational colleges. 


\section{Resoures mobilizing related functions}

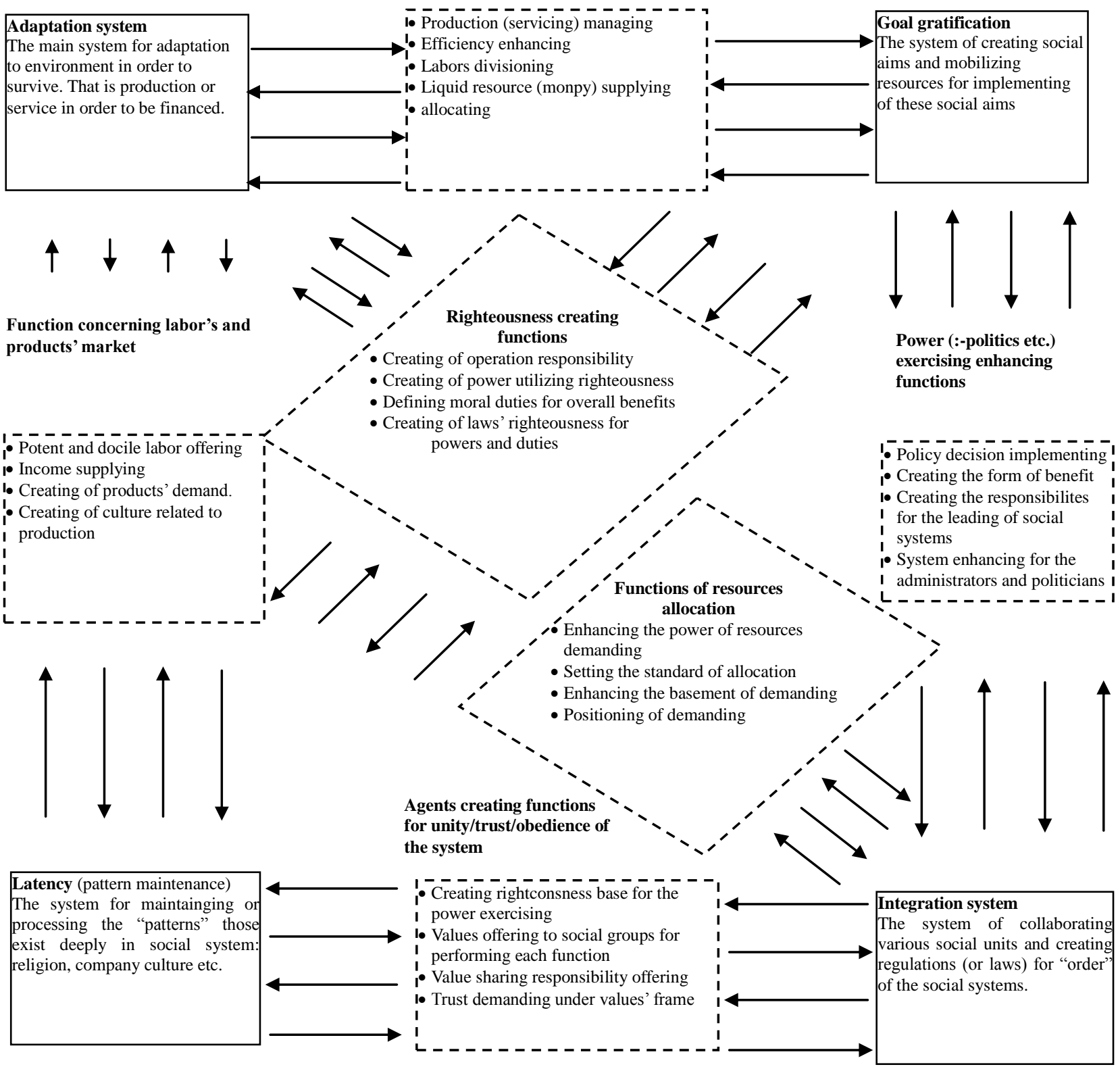

Figure 2. Analysed diagram of Talcott Parsons' schema being main functions of social systems. Source: Kazuo, 1974. Notes. "sending" arrows means agent's feeding the denoted functions (information) for the "receiving" agent. For example, A system's agents implement or involve in the "production" (including "servicing") for G subsystem.

\section{K.J. METHOD}

K.J. Method was invented by Japanese anthropologist Kawakita Jiro and also conventional well-known data compositional idea creation wisdom. It is hierarchically data processing method as denoted in Figures 3 and 4 . The main principle is that the data will denote their own logics.

\section{The Overall Analysis and Writing of Diagrams}

These were implied in Figure 5. 

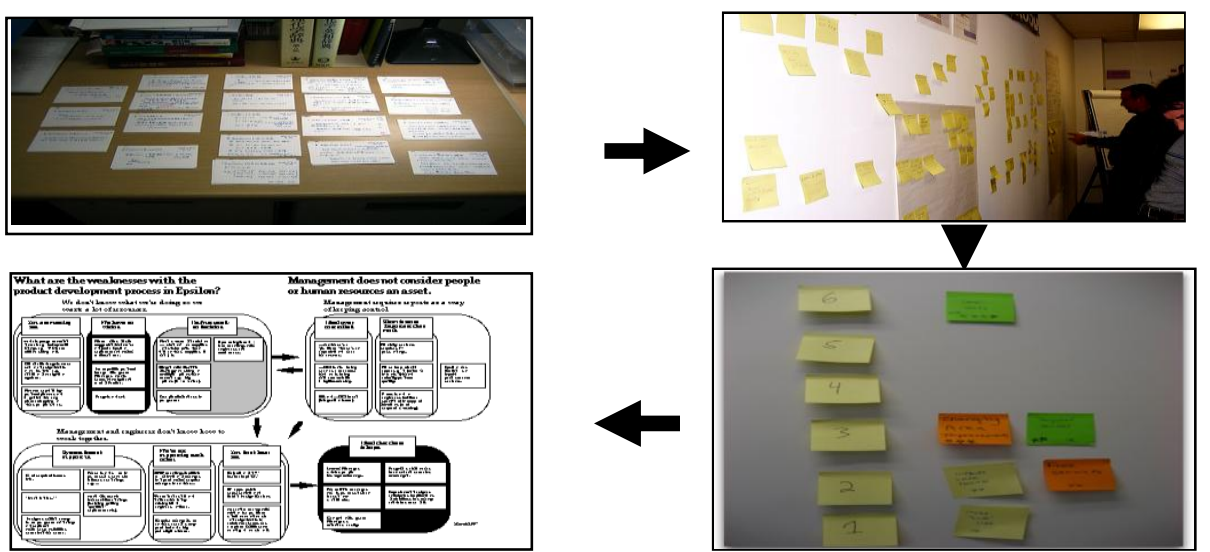

Figure 3. The example pictures of K.J. method.

(Idea creation during processing data)

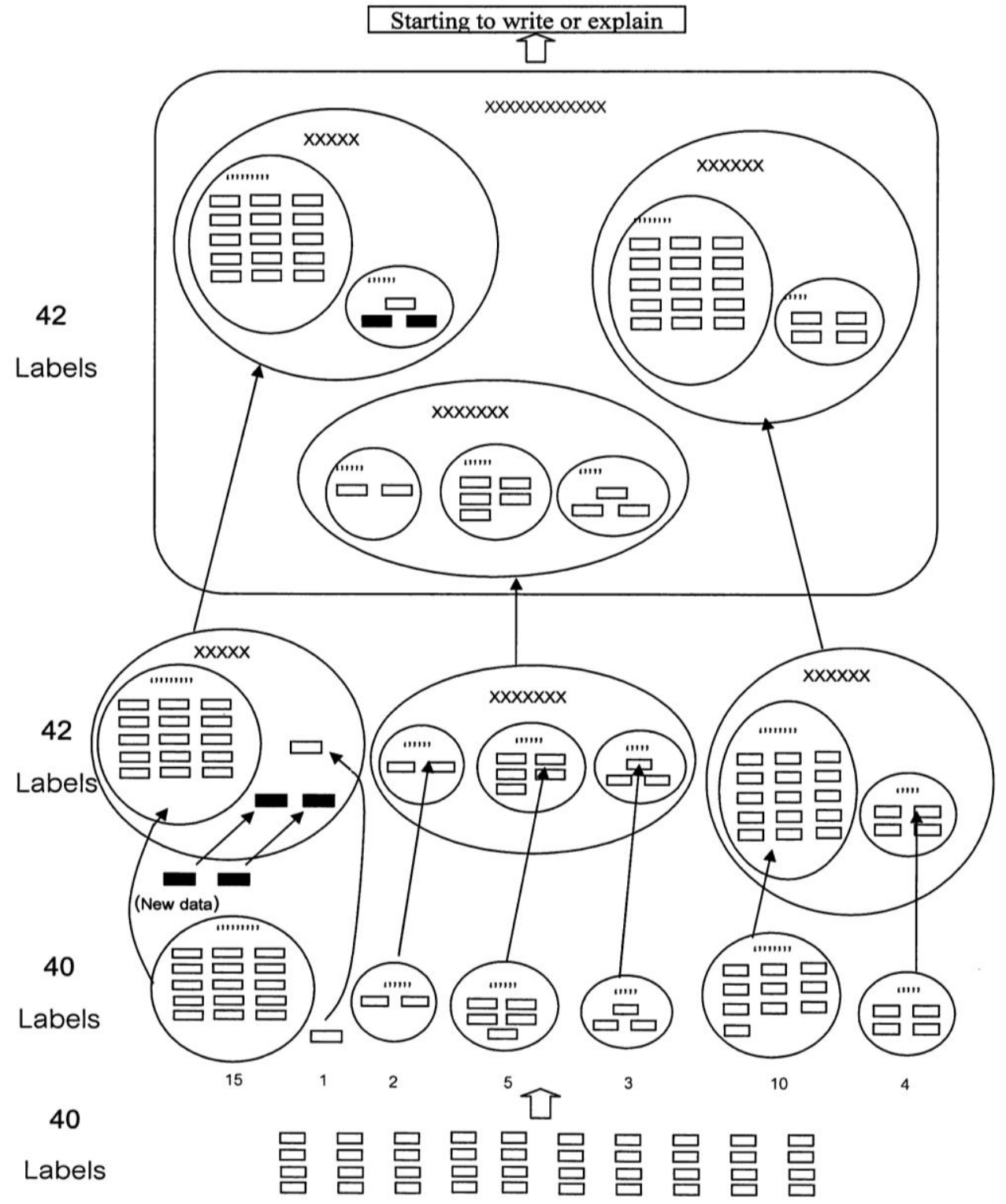

Figure 4. The concept's picture of K.J. method of processing 40 labels (40 verses). 


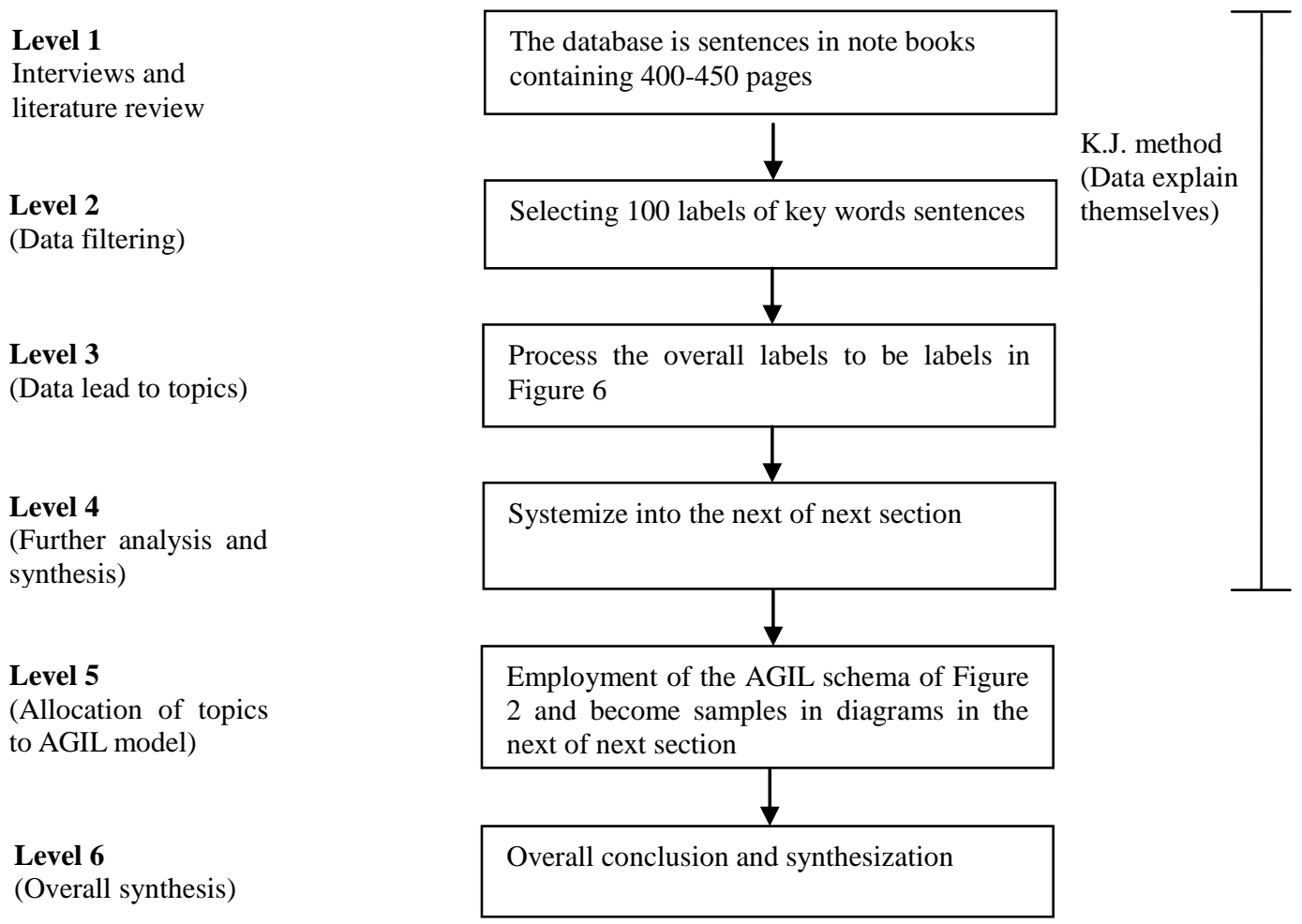

Figure 5. Qualitative processing of the interviews and secordary data by utilizing K.J. method and AGIL schema.

\section{The Brief History of the Ministry of Education and Office of Vocational Education Commission}

\section{Ministry of Education}

In 1932, the year of transition into Thai democracy, the national compulsory education plan was firstly decreed. The educations were equipped with general and vocational ones which this pattern had prevailed until recently. In 1936, 1939, 1951, and 1959, those education plans had been revised repeatedly. In 1960 the 1st National Education Development Plan had been decreed in line of the 1st National Social and Economical Plan from 1961 to 1966. The 2nd to 8th ones had been decreed extending from 1967 to 2001. During these periods, the agenda in currents were the reform of Thai education which have lasted even today. This has been done by National Education Committee which was established in 1992. Notingly, in 2003, the Ministry of Education's functions were streamlined into "4 Pillars", which were: Office of the Education Council, Office of the Higher Education Commission, Office of the Vocational Education Commission, and Office of the Basic Education Commission of Thailand. The thing which should be noted here is recent happening to the agenda so called, "The Second Decade of Education Reform 2009-2018" which emphasizes the "whole life learning with quality" which depicts somewhat educational atmosphere nowadays.

\section{Office of Vocational Education Commission}

The history of vocational education lasted from 1899, which vocational schools were established for training teachers and nurses etc.. In 1941, the Department of Vocational Education was firstly established within Ministry of Education. In 1960 with 1st National social and Economical Plan, the vocation education was set into secondary school and higher education (colleges) in every region of Thailand. In 1977, vocational educations were set into general, technical, and agricultural ones. In 1992, the National Education Committee had increased more than a hundred vocational colleges and even nearly same number in 1999. In the same year, 
the laws that had enhanced education by private sectors including private work place (factory etc.) and establishing private vocational colleges or schooling were decreed. The significant of vocational education had been intensified in 2003 when Office of the Vocational Education Commission became one of the "4 Pillars" of Ministry of Education as mentioned before. It seems that the rise of the north-eastern politicians in those years have enhanced the rising role of vocational colleges into unity of existence of vocational colleges. Finally, the laws that promote vocational colleges to include bachelor degree programs were decreed recently.

The real final note (from observation through conversations) in this section of "brief history" should be written here that in theses 10 years like other public administration through out the country, the political rivalry from "power and money struggling" also prevailed in vocational colleges or Ministry of Education itself. This phenomenon seems to obstruct the strength of education reform schema, but in contrary, the rise of politicians from region (especially north-east) has seemed to promote vocational colleges themselves either real budget or public atmosphere.

\section{Main Findings From the Interviews After Employment of AGIL Schema and K.J. Method}

\section{The Main Characteristics of Vocational Colleges Administration}

The main characteristics are:

The pubic vocational colleges which outnumber the private ones, are centralized into the Office of Vocational Education Commission within Ministry of Education (as mentioned before). The central administrators will send the philosophy, policy, regulation functions outlines, agenda, central schooling contents, approvement of personnels and other etc. to the regional colleges and also receives the feed-back and forth (The benefits of this streamlining effects should be noted here).

Each vocational college administration is centralized to the hierarchical administration of directors and vice-directors.

The regional government seems to have very small impact to the administration of vocational colleges (from interviews) which seems to be not always negative phenomena (assessed by writer).

From north-east vocational colleges surveying, the infra-structures of the colleges including computerization are modern and possess vitality. The streamlining to the central government's good effects are sensed.

The personnel administration including the approval of directors and deputy directors is centralized to the Ministry of Education (by examination and approval of committee).

Recently, by the central policy, the coordination between colleges and private companies or factories is promoted and seems to be in good progress. The symbiosis between public administration of vocational colleges and private sectors seems to be on rail (from observation). The adaptability of people (administrators), themselves Thai people can not be neglected as one of key factors in this area of study (from observation).

Like other Thai public administration the "Muda" (the "waste" in operation management's term) has been sensed in the Minister of Education itself (in some sense, more than regional vocational colleges administration). This might be related to the "people rifts" in any Thai public work place been observed by the writer.

Even the infra-structure at the regional vocational colleges seems to be good, the difference between the endowment of the central educational public institutes (universities) and vocational colleges is griefly incomparable (for example, the research fund for any one researcher in Bangkok well known university is roughly three times the research fund for the whole one vocational college) and unmentioned by any party even the regional politicians. Thankfully, this difference seems not to have any antagonism among people. Any way, 
for the time being, the symbiosis seems to go on.

Still, the vocational education seems to be possessing vitality with adaptability and flexibility to any transition partly because of top-down bureaucratic systems' prevalence (assessed by writer).

\section{System of Sentences of the Macro Problems}

\section{The Diagram of System of Major Problems}

This diagram is the highest level in the denotation of systems (labels) from K.J. method (see Figure 6).

\section{Findings of Overall Sentences of Macro Problems}

1. Macro economic related sentences.

1.1. Paddy field, community and vocational colleges related sentences.

1.1.1. Cities and regions discrepancy.

1.1.2. Curriculum disacknowledgement of the relation between knowledge's and community development.

1.1.3. Insufficiency of personnels in agricultural regions due to the spill-out of graduates to other sectors.

1.1.4. Few students in agriculture colleges.

1.2. Decrease of demand toward graduates due to the insufficiency of industrial investment.

1.3. Huge discrepancy in endowment between main engineering schools and north-east vocational colleges.

2. Central public administration and central politics related sentences (Education Ministry).

2.1. Centralizing necessity of complex, redundant, and openly changing of administrators and politics concerned systems.

2.1.1. Directing of activities of colleges from central.

2.1.2. Complex structure of the related administration units.

2.1.3. Frequent transitions of the policy's agenda.

2.2. Power exercising of politicians and clique formation (for example, the transfer of college directors).

3. Image-morale-culture of prejudice related sentences.

3.1. Morale problems of the teachers.

3.1.1. Hard compulsory work of the teachers including admin works and self-writing works for promotion.

3.1.2. Welfare problem of assistant teachers (low salary).

3.2. Prejudice against vocational college student (image problem).

4. The problems of regional administration and transfer of autonomy to regions.

4.1. The problem of restriction of regional administration potentials except to budget potential.

4.2. The difficulty of regional administration potential toward the area of vocational colleges.

5. The problems concerning curriculums and extra-activities of the students.

5.1. Curriculum's problems.

5.1.1. The old-fashion of the curriculums.

5.1.2. The limits of the potential teachers.

5.1.2.1. Contradiction between "common" knowledge of engineering school of teachers and "particular" aspects of ideal vocational colleges's curriculum.

5.2. "Students" problem of insufficient potentials.

5.2.1. Insufficient capability of math of students.

5.2.2. The inability of some students (20\%) to pay college's fee in some colleges.

6. The problems of contradiction from "common" or "particular" direction of the curriculum. 
6.1. The vast areas of vocational colleges' possible areas of learning nowadays.

6.2. The high cost of endowment of vocational colleges in vast areas.

7. Some unachievement of the policy.

7.1. Unachievement of the agenda that students are possible to select their own study area.

7.2. Unachievement policy for allocation goal of number of students of 50-50 in ordinary education and vocational one.

7.3. Insufficiency of entrepreneurship of the graduated students.

7.4. Insufficiency of elites from vocational college in country.

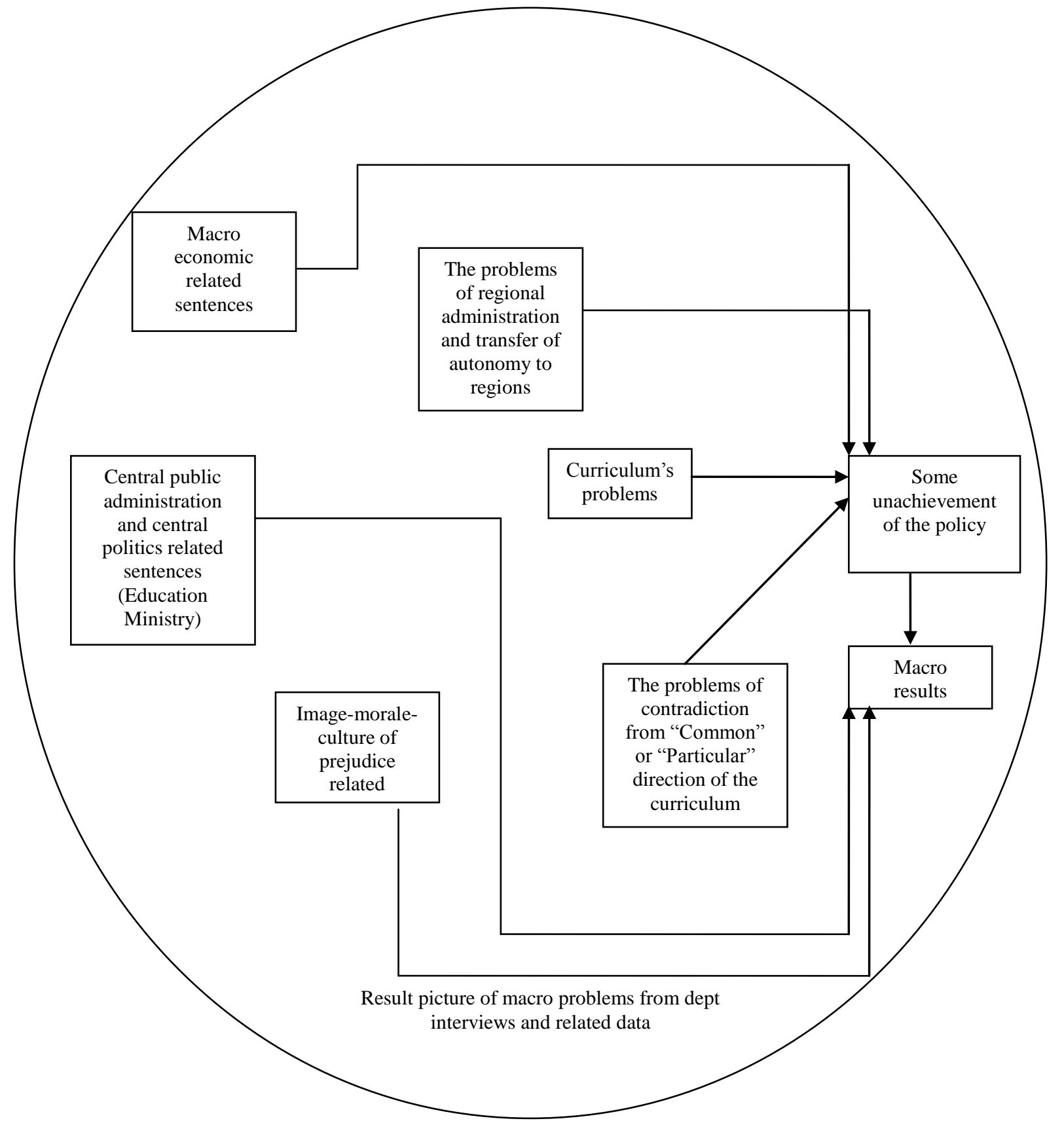

Figure 6. The result picture of macro problems from 400-450 pages of notes. 


\section{Results From the Streamlining of the Macro Administrative Problems of North-East Vocational Colleges}

From the streamlining of the problems, contents below have been identified and analyzed.

The declination of agricultural sector and fuzziness of the direction of economy itself induce the ambiguities of direction of agricultural and technical vocational colleges, which is the direction of curriculums themselves. This problem might decrease faith in career of teachers and personnel themselves. Moreover, some agriculture colleges (one type of vocational college) have decreasing number of enrolled students as well as some what prejudice from surrounding societies.

Although the streamlining and centralizing of public administration of vocational colleges seem to be needed among too complexity of the policy practices. The reshuffle of the personnel's both central ministry and regional colleges into cliques power structure also induces corruption and "power-related" problem.

The cultural prejudices against vocational colleges graduates impede social opportunity and capability itself. Partly, this comes from the rampants of the street fighting among vocation colleges mostly in Bangkok at urban congesting areas around at least these 40 years. The government from Mr. Thaksin's side, well equipped with marketing technology, tried to reimage vocational colleges with some degree of success. An example of such activities is the helpings extended to the people by students in technical matters by out of charge.

\section{Some Derived Diagrams' Examples (System Identification) of the Main Investigation (Figures 6-12)}

The process of obtaining derived diagrams is the Hypothesis creation process itself. More specifically, the diagrams themselves are Hypotheses.

\section{Some Implication From the Main Findings}

Nowaday, the main vocational education is done by centralized public administration. The role of regional government in this area should be considered extensively in future together with the liberalizing in this area. (By now, only five or six well-know vocational institutes are just emerging).

The major problems in Figure 6 and the breakdown of these just constitute the area of vocational education which should be scrutinized further in future research.

Ordinarily, the administration of the vocational colleges is done by function prescription level (decree), agenda prescription level, and area's college autonomy level. These were called "Funciton-Agenda-Area" usually by directors of the colleges. Our analysis in this research seems to be meta-functions above of these three levels. Thus, we have to further study these derived meta-functions and deduce and induce it into "Function-Agenda-Area" terms for utilization.

Ideally, the relationship among sub-problems or major problems will be identified by the Figure like Figures 7-12. These should be explored further.

One of the main methodological problems is the involvement of the "Agents". One way of soluting this problem might be the introducing of agents connected with the "sending arrows" and "receiving agent" as mentioned before or more explicity, the locating of "Agents" into the macro blocks of A-G-I-L (not the dotted ones). Katai Osamu have introduced the novel method which could include "Agents" in Figure. This will be mentioned again in Appendix Figure A1. 


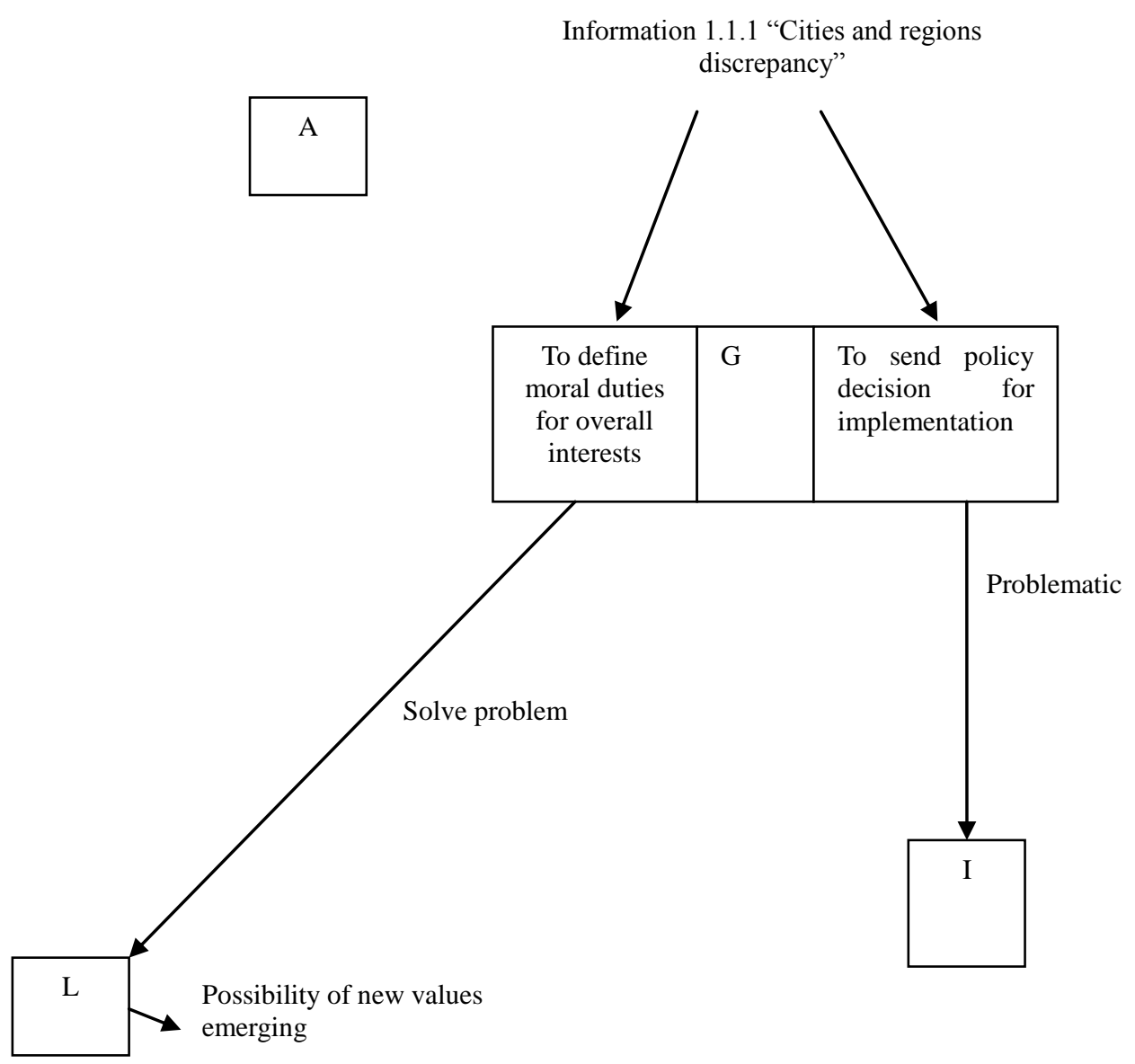

Figure 7. Some likely impact to systems when information 1.1.1 enters through G system.

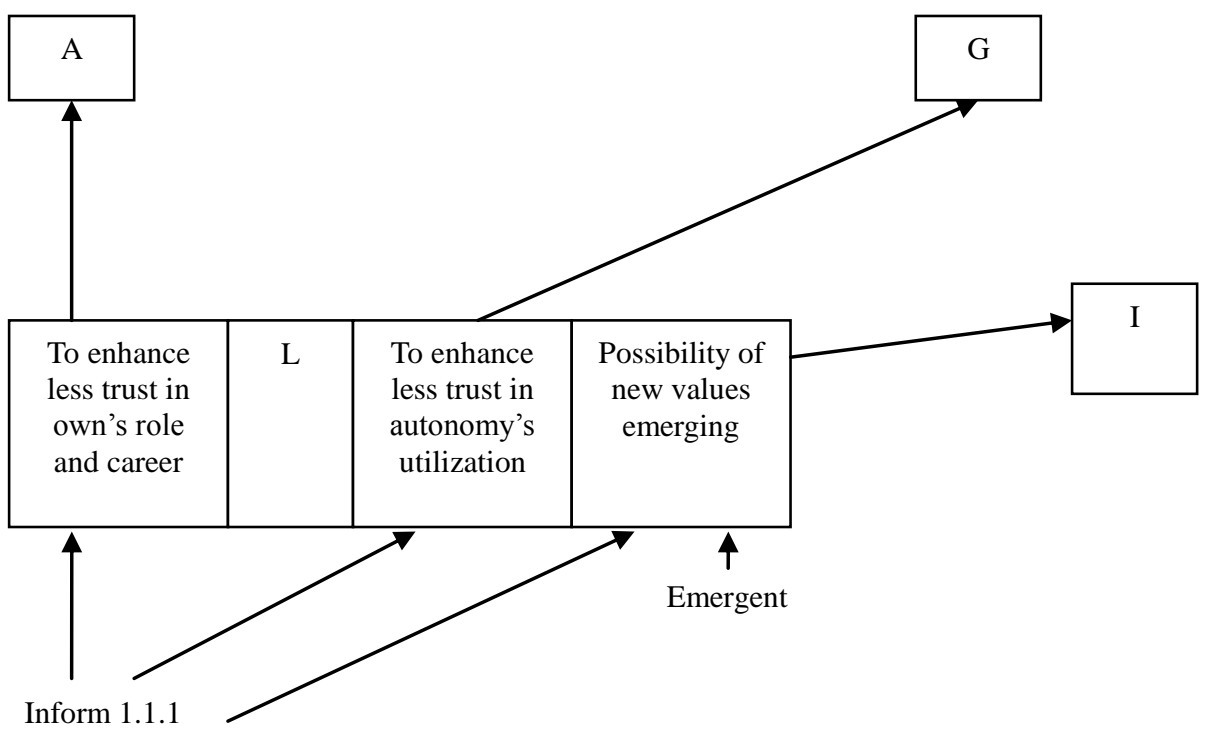

Figure 8. Some likely impact to systems when information 1.1.1 enters though L system. 


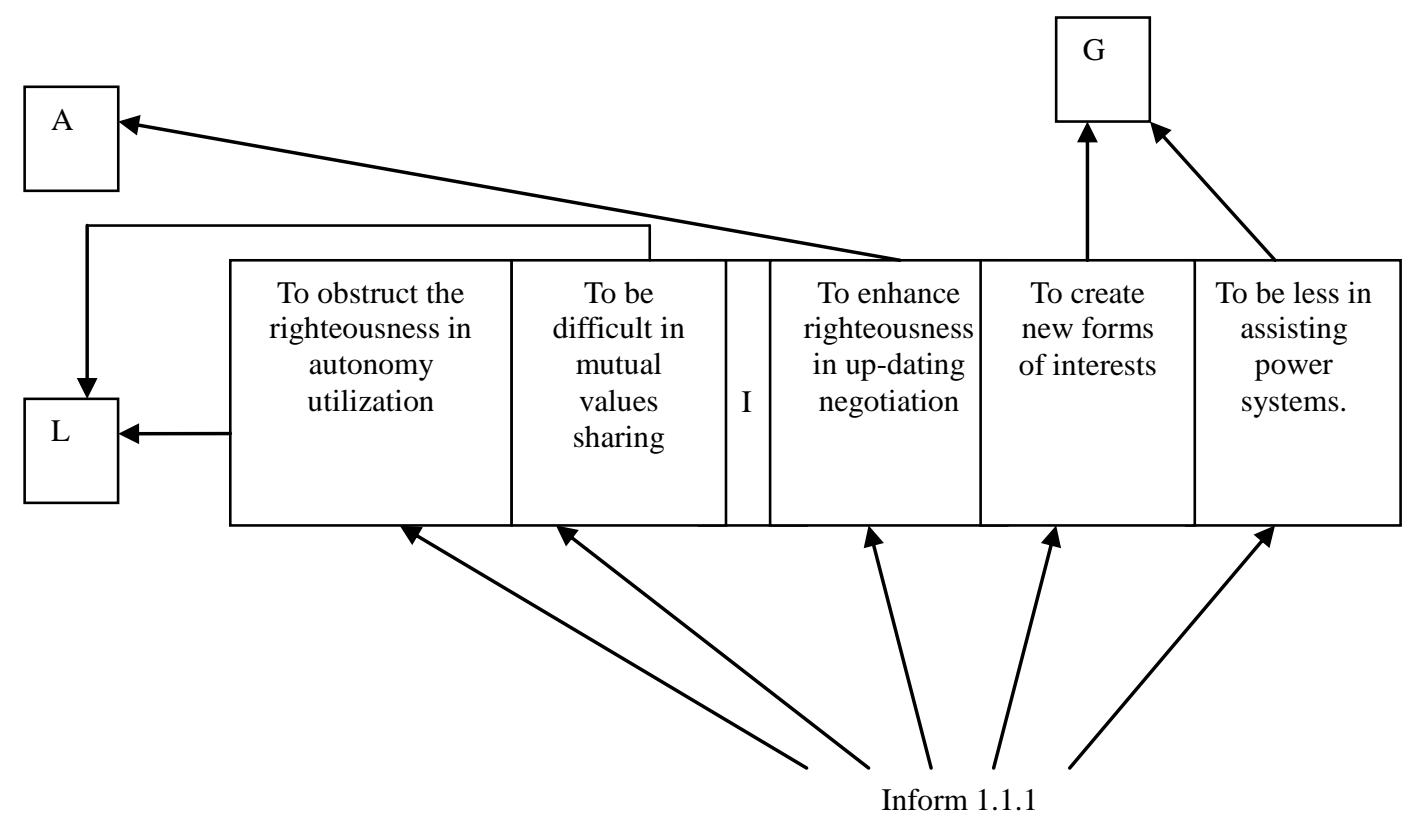

Figure 9. Some likely impacts to systems when information 1.1.1 enters through I system. Note: The influence of information 1.1.1 entering I system might be more inert than entering other system for the time consuming of the legal process.

Inform 1.1: Insufficiency of personnels in agricultural regions due to the spill-out of graduates to other secors

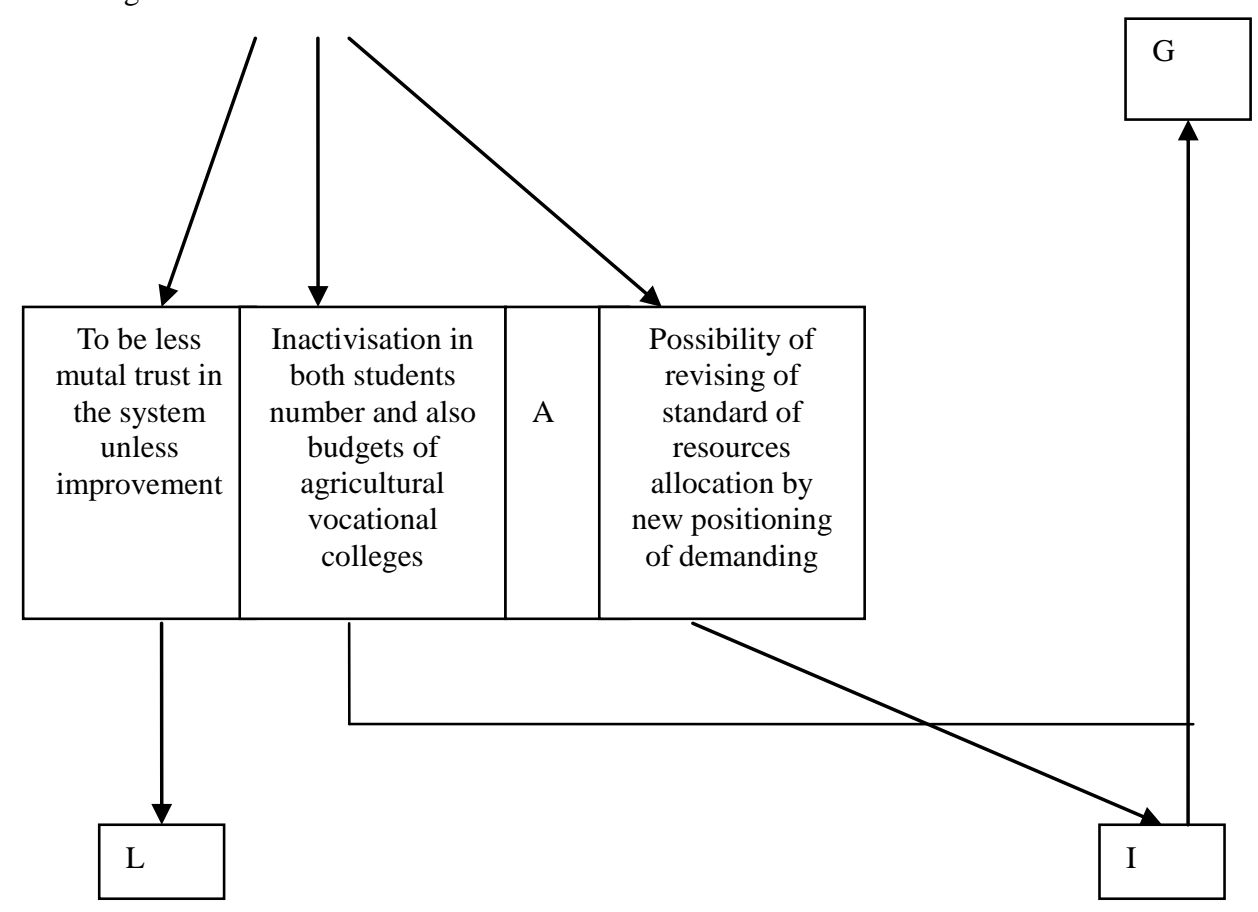

Figure 10. Some likely impacts to systems when information 1.1.1 enters through A system. 


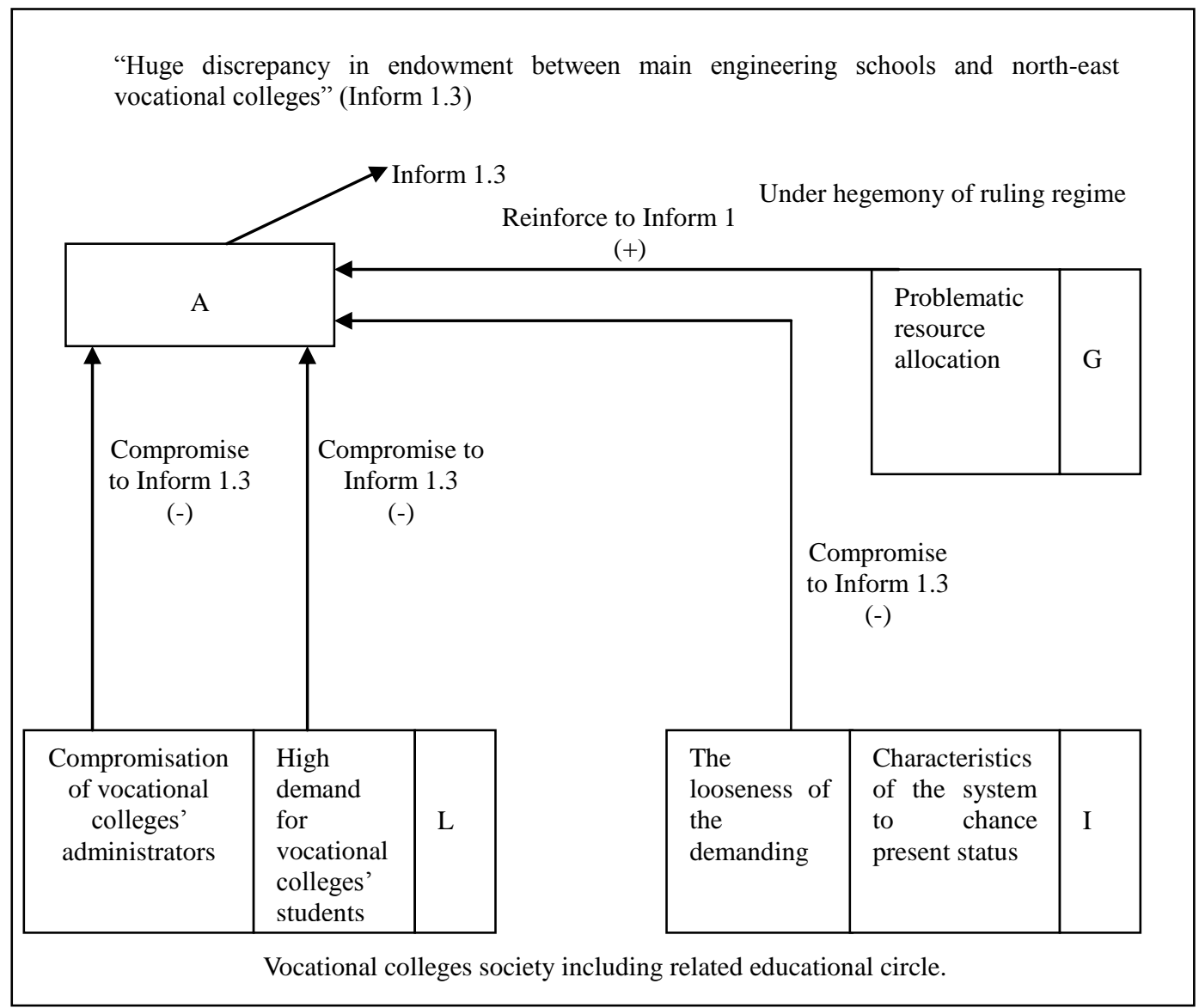

Figure 11. The clues toward "huge discrepancy in endowment between main engineering schools and north-east vocational colleges" (Inform 1.3).

\section{Why Employing AGIL Schema Not Other Sociological Methodologies}

Firstly, by employing AGIL schema, the writer took the stance that "total social structure" be existing. It corresponds to the aggregated phenomena. Other sociology approaches focus equally on "structure" on human factor so-called "individualistic approach". Utilization of AGIL schema might stem from the writer's belief that Thai society is unbelievably not too difficult to predict if data being provided and is vulnerable to the structures norms or regulations. Moreover, it is not too much complex as thought from first glance.

Secondly, AGIL schema is something that takes the hypothesis of ideal condition for maintaining or stabilizing the social system which is like "symbiosis" concept.

Thirdly, by the above approaches, the writer took the stance of "operation" more than "explanation".

\section{“Aspect System's" Character of Social System Manipulation}

Every manipulating, analyzing or synthesizing of social system needs "each approach" or grasping particular aspect which varies upon each sociologist. The "correct explanation" might not exist. This might result in "heuristic" and "operation" approach to social systems in artificial intelligence' or system theory approach itself.

\section{Concerning “Opened System” Problem}

Thai social system identification confronts the "opened system" controversy. For example, we often notice the influence of schools alumni to the operation of the reshuffle of high ranked personnel's (like related politicians). 
In writer's understanding, Luhman solves this problem and complexity problem by reducing "actions" or "activities" into "communications", and selects the objects of analyzing in "system" in a particular way. This should be discussed in the future.

\section{The Redundancy of Variables in A-G-I-L's System}

In abstract terms, the units of A-G-I-L system are "actions". The writer's approach to this is rather ambiguity. By granted, the writer took it as vague "activities" done by "agents". Some of these "activities" or "agents" or tentative "actions" might be redundant in sub-systems of A-G-I-L system.

Another aspect is the redundancy of shadow of unofficial organization over official organization. This counteracts the grasping of system. It also counteracts the writer's opinion mentioned before that it is not too difficult in predicting the behavior of Thai social systems. Further discussion is needed.

\section{The Novel Method of Including “Agents" Into the System of “Actions” (Activities) by Osamu}

KATAI ISAMU is Professor at Kyoto University. He was the student of Professor Iwai Sosuku who was the teacher of the writer. Professor Iwai had published many theses in the area of group dynamics and also educational approach (operational approach) to social system which could be utilized in Thai social systems. Both teachers selected the stance of "balancing" or "symbiosis" to the analysis and synthesis of social system via "information" (balancing itself is the natural mechanism).

In Katai Osamu papers, he introduced "Leibnizian space and time", "occurrence net", and "Peirce's existential graph" to his novel model.

At this moment, the writer has the sense that his model could be applied to psycho analysis and communication areas in Thai society. The model itself includes "agents" and "actions" (or "activities") at the same time to the illustration of social system which seduces the writer to pursue in this area. At this, hopefully, the possibility of finding the clues to "symbiosis" of the social system emerges.

Luhman (very influencial sociologist) also modeled social systems into "communication" and selected the objects of analysis in special way. These should be pursued further together with Giddens' writings.

\section{Conclusions}

In this writing, the writer has applied AGIL schema and Aoi Kazuo's AGIL's elaborated diagram to analyse, synthesize, and identify the macro problems of north-east vocational education in Thailand from field surveys and other secondary data. Basically, K.J. method has been employed intensively. The brief history of the related institutions has other been introduced.

The detail of main findings, system of sentences of the macro problems, some derived diagrams examples (After AGIL schema applying) and also implication from the main findings have been illustrated.

Lastly, from Appendix Figure A1 also, the writer should utilize Katai Osamu model method to include "agents" also into system of "actions" (or "activites") hopefully in the future with extensive study of Luhman and Giddens sociology.

\section{References}

Aoi, K. (1974). Shakaigakku Koza 1, Rironshakaigakku. Todai Shuppa Kai: Publication Association of Tokyo University.

Jonathan H. T. (2003). The structure of sociological theory. Wadsworth: Thomson Learning Inc..

Osamu, K., Hiroshi, K., Takayuki, S., \& Agira, N. (2010). Formalizing coexistential communication as co-creationof leibnizian spatro-temporal fields. AI\&Soc., 25, 145-153.

Osamu, K., Katsushi, M., Takayuki, S., \& Hiroshi, K. (2007). System design of "Ba"-Like stages for improvisational acts via 
Leibnizian space-time and Peirce's existential graph concepts. AI\& Soc., 22, 101-112.

Tumtavitikul, S. (2011). The study of systems identification of public administration for the development of public vocational colleges in north-east of Thailand. Institue of Human Resource, Thammasat University, Bangkok, Thailand.

Yoshifumi, T., \& Tsuruyo, F. (2008). Thailand in motion: Political and administration changes 1991-2006 (Tai Seiji Gyosei No Henkaku: 1991-2006). IDE Research Series, No. 568.

Appendix A

"Spill-out of the graduates" (1.1.3)

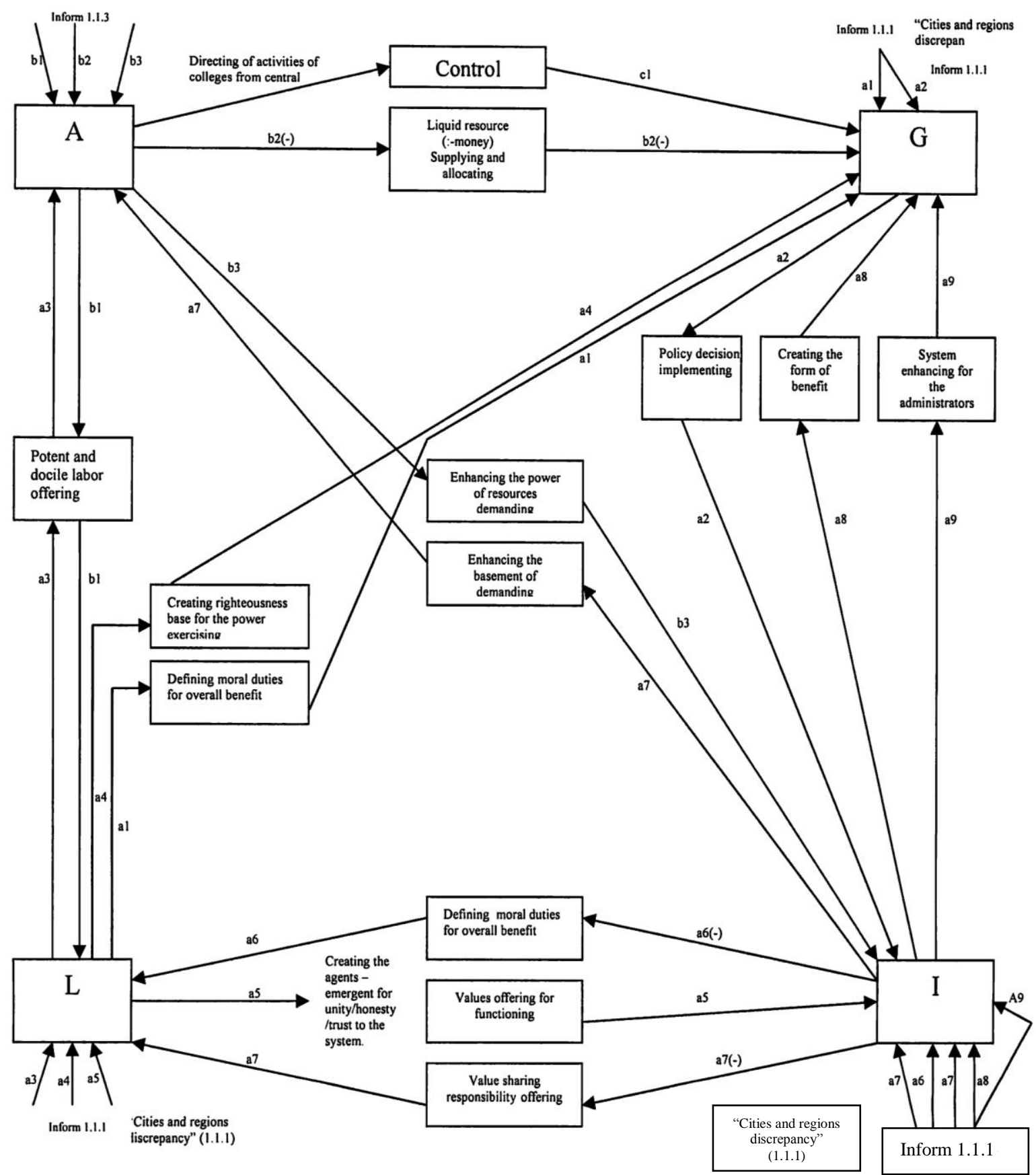

Figure A1. Some related methodological issues to this research (Inform 1.1.1 and Inform 1.1.3). 